\title{
Application of preliminary risk analysis at marble finishing plants in Recife's metropolitan area
}

\author{
Melo Neto, Rútilo P. de and Kohlman Rabbani, Emilia R. ${ }^{\mathrm{b}}$ \\ ${ }^{a}$ Specialist in Occupational Safety Engineering, UPE/POLI, Recife, Pernambuco, Brasil. rutilo@br.inter.net \\ ${ }^{b}$ Adjunct Lecturer, UPE/POLI/PEC/LSHT.
}

\begin{abstract}
The finishing of marble occurs in quarries all over Brazil, being the most significant dimension of the ornamental stone sector, with 7,000 businesses. Recife's Metropolitan Area (RMR) contains approximately 106 marble quarries, 25 of them unionized. The study focused on the application of Preliminary Risk Analysis, conducted at two unionized quarries: M1, a small business; and the second, M2, considered a micro enterprise. In this analysis both the administrative and the productive sectors were evaluated. The fieldwork was done in the month of December 2010. The study revealed that the two quarries carried moderate risks in the administrative sector, mainly due to ergonomic factors, and that in the productive sectors the risks were high, specifically because of excess noise, dust material, and precarious electrical installations. Using the results of the qualitative analysis as a base, the need for quantitative study presents itself in order to determine the most adequate modes of protection to be of assistance in the management of these risks, guaranteeing the safety and health of the worker and consequently the improvement in productivity in this sector.
\end{abstract}

Keywords: Risk evaluation. Preliminary analysis of risks. Marble works

\section{Introduction}

Marble refinement is widespread in Brazil and, in economic terms, is the highest achiever within the ornamental stone sector, with more than 7,000 companies involved. (CHIODI FILHO, 2009).

Recife's Metropolitan Area has an estimated total of 106 marble refinement plants, where 25 take part in the mining and stone processing union in the State of Pernambuco (SINDIPEDRA, 2010).

This study is focused upon the application of the Preliminary Risk Analysis (PRA) technique applied to the finishing process conducted at two unionized marble finishing plants: the first, $\mathrm{M} 1$, represents a small business and the second, M2, is considered a microenterprise.

In this analysis the administrative and production sectors were evaluated, thus revealing the following operations of the production process: (i) unloading and storage of slabs and blocks, (ii) cutting, grinding, polishing of slabs and assembly of ornamental pieces, and (iii) loading of final products.

Figure 1 schematically represents the sequence of the finishing operations, making it possible to visualize a simplified analytical flow of the production process at marble finishing plants.

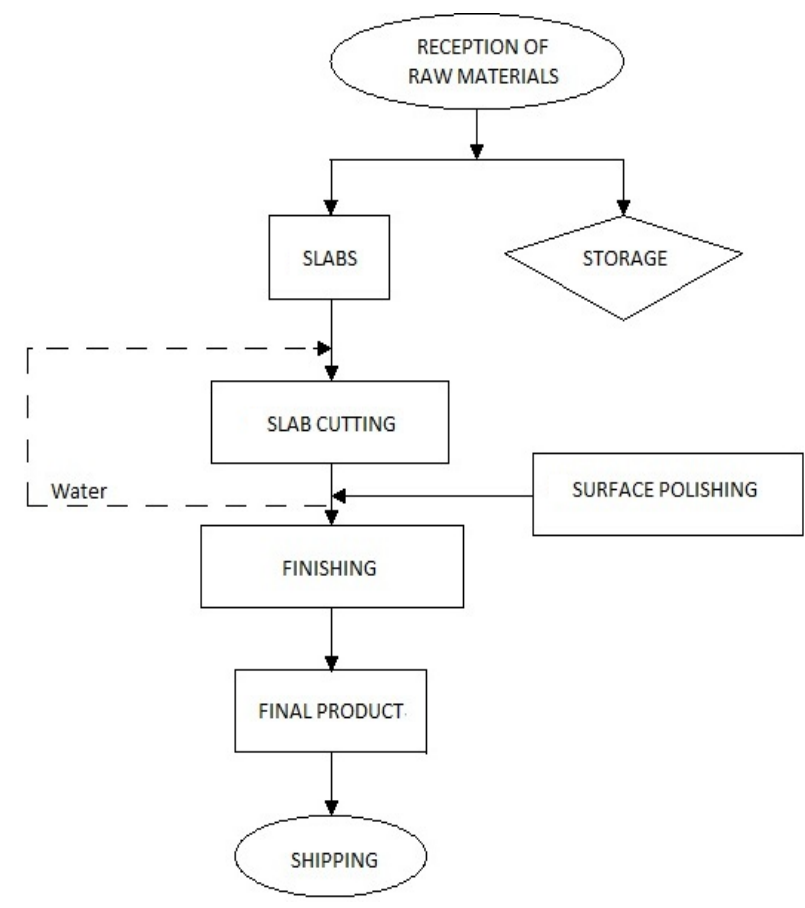

Figure 1 - Flowchart of finishing operations at marble finishing plants.

\section{Methodology}

The research consisted of a qualitative analysis of the occupational environment at two marble finishing 
plants in the Recife Metropolitan Area in order to map out the main hazards during the operating stages of the finishing process. The field study was conducted from the $7^{\text {th }}$ to the $28^{\text {th }}$ of December 2010 . The qualitative assessment was based on the APR technique for the preparation of a situational diagnosis related to Occupational Safety and Health (OSH) management. To achieve this, visits were made to the marble finishing plants in order to monitor and describe the various stages of production. Interviews with directors and employees were conducted, documents were analyzed, accidents were recorded and checklists were applied.

The presentation of results was carried out by developing an occupational safety matrix, initially by the identification of tasks with the number of employees performing each function, using descriptions of these functions from the Brazilian Occupational Registry (CBO), and an overview of the basic activities performed at marble quarries along with the risks associated with each function.

Two checklists were developed for the initial characterization of the scenarios. The first, with 160 questions, was aimed at marble finishing plant directors, based on regulatory standards $5,6,7,8,9$, $10,11,12,15,16,17$ and 26 (BRAZIL, 2010), and filled out using analysis of documents, interviews, and observation. The second, with 13 questions, was applied to the directors of both marble finishing plants and covered the Occupational Safety and Health Management Systems (OSHMS) referring to convention number 148 of the International Labor Organization (ILO), technical specification OHSAS 18001/2007, and regulation ISO 19011/2003.

A layout of the marble finishing plants was also created in order to facilitate the visualization and localization of the occupational hazards identified.

\section{Results}

The study revealed that both marble finishing plants M1 and M2 presented moderate-level ergonomic hazards in the administrative area. In the manufacturing sectors, serious and imminent chemical, physical, biological, accident risks, and ergonomic OSH hazards were observed. The area where workers were subject to the most hazardous conditions was where there was cutting, grinding, and polishing of slabs, and mounting of ornamental pieces. Notably there was the excessive noise, dust, and the presence of poor-quality wiring, as shown in Figure 2.

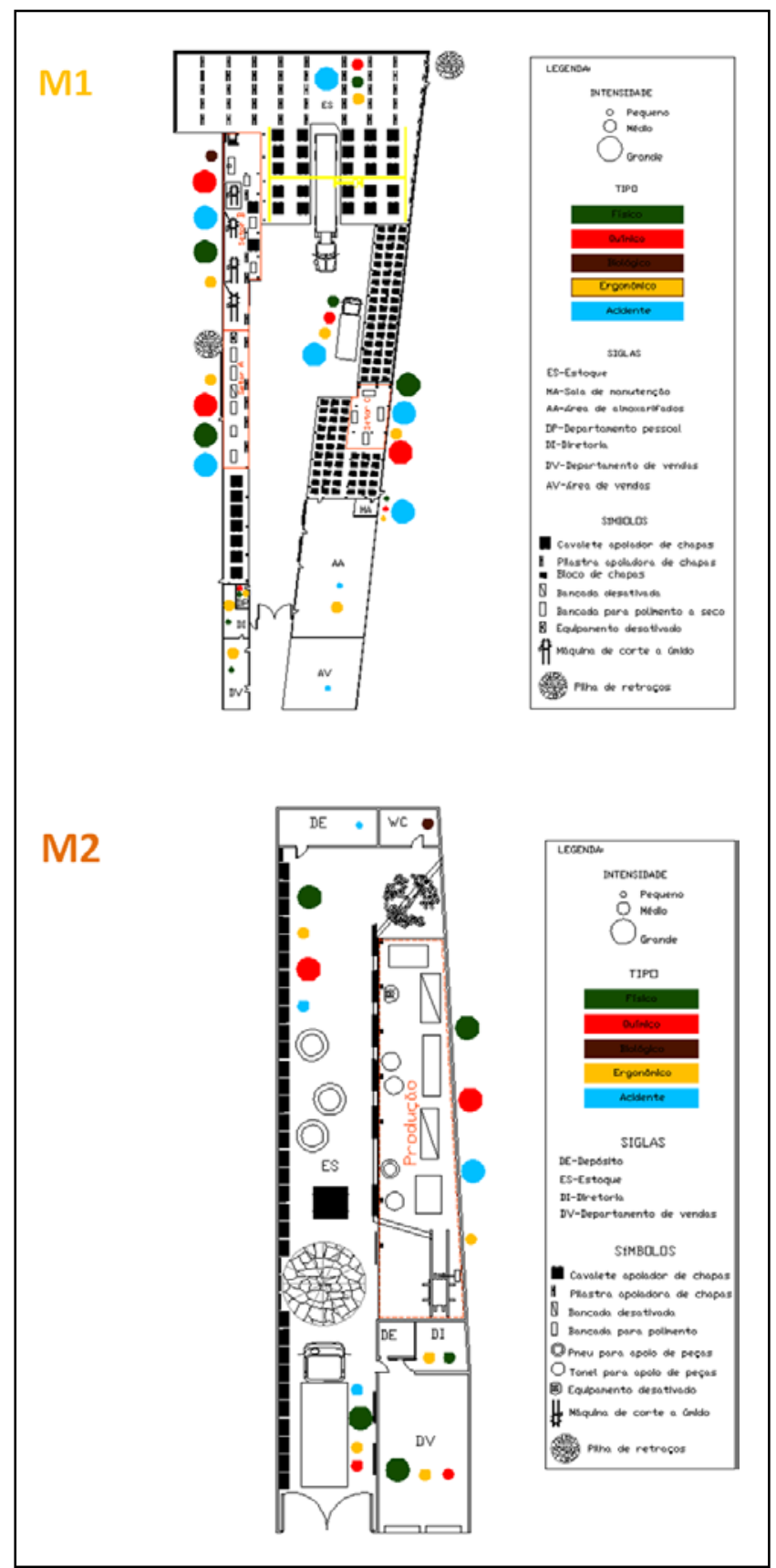

Figure 2 - Map of occupational hazards at Marble Finishing Plants M1 and $\mathrm{M} 2$.

\section{Recommendations}

Based on the results of qualitative analysis developed in the two marble finishing plants studied, it is advisable that quantitative studies be performed so as to determine the levels of noise and dust present, and in turn define the most appropriate protection measures, assisting in the management of risks to ensure worker safety and health, consequently improving productivity in the sector. 


\section{References}

[1] Chiodi Filho, C. Perfil de rochas ornamentais e de revestimento -

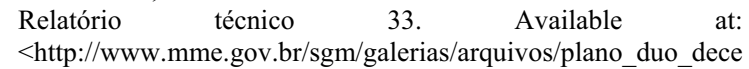
$<\mathrm{http}: / /$ www.mme.gov.br/sgm/galerias/arquivos/plano_duo_dece
nal/a_mineracao_brasileira/P23_RT33_Perfil_de_Rochas_Orna mentais_e_de_Revestimento.pdf $>$ Accessed on: $12 / 10 / 2010$.

[2] SINDIPEDRA. Cartilha do sindicato da indústria de extração e beneficiamento de pedras do Estado de Pernambuco, 2010. 